\title{
Teacher training - the interplay of IT and society
}

\author{
Christian Görlich and Ludger Humbert \\ Studienseminar für das Lehramt für die Sekundarstufe II, Museumsstrasse 8, D-59065, Hamm, \\ Germany
}

\{goerlich|humbert\}@semsek2.ham.nw.schule.de

Key words: Ethical/Ethics, Knowledge Management, Learning Environments, Teacher Training, Values

Abstract: This paper emphasizes the necessity of approaching the conference agenda
with a more precise terminology and more practical and verifiable projects. It
proposes that data related to current on-line learning projects could be made
available for empirical research to provide theoretical grounding and facilitate
reconstruction of sociological questions. The paper argues that purely
scientific approaches are too narrow and limited in scope. It draws attention to
ethical implications and supports Merton's view of the decisive role and
significance of values to be observed. Focusing on the debate of computer
supported collaborative learning (CSCL) the authors suggest that any research
should consider in a more systematic and consistent way than before the
individuals concerned, the constantly changing structure of social groups and
the given social context. The authors build on the work of Holzkamp (who
demanded a theory of learning based on the individual without ignoring the
social context) and Foucault (who considered educational structures and
institutions served to guarantee the efficiency of forms of learning and
function as an element of control and social order). They stress that change in
a CSCL environment may result in fears and anxieties that have to be given
due consideration. The authors report on a current CSCL project in teacher
training. Within the context of clearly defined academic research trainees
explore and test new forms of cooperation and "knowledge management". This
is effected by creating and working on virtual learning stations in different
places and at different times. Preliminary findings indicate that educational
bureaucracies and government offices need to adjust now and in the future.

The original version of this chapter was revised: The copyright line was incorrect. This has been corrected. The Erratum to this chapter is available at DOI: 10.1007/978-0-387-35663-1_34 
The authors trust that more empirical data will become available for educational research focussing on the learning biography of adult learners.

\section{IT - THE HISTORICAL AND SOCIOLOGICAL PERSPECTIVE}

Using the word "new" in the context of new media and IT may suggest preconceived notions we are not aware of. It seems to suggest that not only the subject matter at hand (in this specific case computer studies/IT) is "new", but also the related problems. Surely this is only true in some respects - in other respects it requires modification. No-one should forget the historical dimension of current issues and controversies. There is no doubt that any debate today will benefit from consideration of such historical studies.

To a certain extent new technologies are means of production which interact in various ways with different social classes and élites. In this context our attention should be focused on the wealth of accumulated knowledge and acquired skills in any given society. This is one of today's most crucial assets. Against this background "the interplay of 'new' technologies and society" does have a comparatively long tradition of related problems.

Modern philosophers have found it increasingly difficult to refute the Marxist notion that socio-economic forces exercise a stranglehold on all cultural phenomena. Neo-Marxists have often simplified and reinforced these tenets. It may be superfluous to point out that Marx himself had a more differentiated concept of the process of (and consequently the means of) production.

In both sociology and cognitive science there have been a number of new approaches since the beginning of the 20th century. Representatives of these new schools of thinking are the German philosophers Max Scheler and Karl Mannheim. This school is widely known and recognised as the "traditional knowledge-based sociological approach". Without ignoring its historical merits this approach has been severely criticised in respect of the limitations of its questions and its simplistic answers.

The structural and functional approach has replaced these post-Marxist schools of thinking. Two factors have proved to be decisive - the influence of natural sciences (biology in particular) as well as the negative consequences of scientific discoveries. This approach has paid special attention to systemic rather than isolated causally related relationships. The work of Robert K. Merton is important in this context. For Merton science is 
more than just accumulated knowledge, far more than a variety of skills. Science is:

"an organized social activity of men and women who are concerned with extending man's body of empirical knowledge through the use of these techniques. The relationship among these people, guided by a set of shared norms, constitutes the social characteristics of science." (Merton 1972)

In recent decades all relevant research has been based on these assumptions. It is simply a matter of speculation if and when a third approach might be used to discuss issues relating to the interaction of IT and society - the sociological and historical approach. IT as such does not have a "history" that would merit and deserve historical studies. Thomas Kuhn has contributed significantly to this school of thought refuting the positivist implications he was concerned about in the structural-functional approach (Kuhn 1962).

This brief survey of sociological and historical schools of thinking has only one objective - to remind us of the fact that the problems we are facing today are not "new" and therefore it may be both useful and worthwhile to refer to these debates.

The reference to Marx serves a second purpose. It reminds us that any debate on the interplay of society and IT is not just concerned with a cognitive interest but genuine emancipation. More is at stake than the interrelationship of technology and society. It is always about power, rule, property and even human suffering and pain.

The objective for our target group should therefore be rephrased as follows:

What exactly is the potential of IT to support the process of Enlightenment? How can this specific Euro-centric approach be reconciled to the global context of IT and the current discussions about a culture clash? Where are the potential stumbling blocks?

Merton has drawn our attention to the issue of the prevalent code of values within this process. In particular he refers to notions like "universalism"," communism", "philanthropism" and "organised scepticism". These notions are the tip of the iceberg of a complex system of values. They need to be discussed against the background of, for example, historical changes, the contrast between norms and reality, the issues of internalisation and educational measures as well as in terms of sanctions for deviant behaviour. It is most informative and telling to conduct research concerned with "the debate on priorities". Here you will discover how significant, and at the same time how controversial, the question of copyright 
and patents has been and still is in the history of modern science. These concepts have undergone a fundamental change.

In this context Merton emphasised the objective of medieval artists to remain anonymous. In contrast to these notions another aspect of the very same discussion emphasises the ever-present function of norms like copyright and patents. So any seemingly irrational pattern of individual behaviour could be explained within a systemic context.

These days the issue of copyright and patents has assumed a new quality and urgency - even if you only consider it indirectly as a form of assessment. Two factors have contributed to this situation - the private use of IT hardware and software as well the increased numbers of those involved in CSCL. An international conference held at Humboldt University (Berlin) in 2001 chose as their agenda:

"Whose knowledge is it? Good to know. Links for an informed society" [http://www.bildung2010.de/gutzuwissen/].

Without doubt free access to IT resources and sources of information will ultimately be decisive for the quality of learning in the future. More differentiated research projects have been presented in the wake of criticism against traditional sociological concepts. Society is an abstract notion that the individual can only experience indirectly in the context of personal daily routines. This premise would enable us to refocus the issue of IT and society against the background of genuinely educational concerns and allow us to explore how the cognitive structures of individuals (pupils, students, trainees and teachers) and their groups (CSCL) interrelate in the context of IT and society.

We have already emphasised the need for an open historical approach. However we need to ask ourselves how valid Kuhn's concept really is. How useful are his terms such as "paradigm" and "anomaly" and his distinction of "pre, while and post-paradigmatic periods"? Are they simply a deluding metaphor or would they open the door for constructive and promising forms of research?

\section{CSCL - RESPECTING THE NEEDS OF BOTH INDIVIDUAL AND SOCIETY}

The public debate around the key phrase "CSCL" is moving towards consideration of the possibilities of transferring computer-assisted processes of co-operative work from the commercial world into education. Members of the latter sector are generally expected to accumulate and communicate 
knowledge synchronously on a local level, though in the first place they should also be enabled to do this asynchronously and in a distributive sense (Wessner et al 2000).

This debate has its origins in the criticism of www-based tele-learning because of its implied limitations in interactivity, individualisation and feedback. Hopes were expressed that improvement on those three aspects would result from the use of CSCL. At the same time it has been pointed out that CSCL is increasingly used in a social context to save resources of time and money.

The authors would like to stress that CSCL has a number of underlying limitations very similar to those of traditional group work. Not all topics are suitable for co-operative work and not every student is in favour of this method of learning. Still, without discussing all pedagogical implications these thoughts can be regarded as being of limited relevance.

In a similar way superior levels of social structures become the focus of attention simply because of their presence and without any clearly recognisable intentions in emancipation. Such a limitation represents a challenge to all reflective pedagogical thoughts.

In his substantial work Klaus Holzkamp (1995) has quite correctly criticised the neglect of the individual in our understanding of the process of learning. In view of currently practiced concepts of constructive criticism of learning, which see the student as an autopoetical system, Holzkamp's criticism may irritate and appear exaggerated. On the contrary: one is likely to accuse cognitive oriented constructive critics of ignoring those indisputably existing restraints of our society with all its limitations in their school of thinking. However, in spite of his plea for an individual oriented school of learning, Holzkamp does not ignore them. His analysis of the genealogy of school as an institution, based on Foucault (1977), explicitly includes the sociological dimension of learning. Still, "society" is a rather abstract term and might only just be experienced by the individual within its direct social surroundings.

We therefore propose a more differentiated view of this complex field of learning. The relatively young institution of learning in modern schools stems from the same ambition to act rationally that can be recognised in the layout of hospitals or prisons. The concentration of a certain amount of people in the same place at the same time probably has its origins in the ambition to act efficiently, but it will also always be closely related to the social function of control. It is obvious that research of local/polylocal and synchronous/diachronous forms of learning not only refer to organisational matters. They go deep down to the roots of society. Any change of this familiar basic order of our society might cause fear such as a loss of control; a kind of fear not unknown to conventional pedagogics. Acting 
pedagogically requires a clearly focussed target. Basically this way of thinking follows an old teleological idea developed in Aristotle's time.

The aim of any individual action can be placed in a hierarchical order of pragmatic actions - at the top of which we find the aim of "leading a happy life". Over the past centuries in German speaking countries the term "education" has taken over the function of the process of focussing on targets. A lot of effort has been expended during each period of time to infuse this term with an appropriate current meaning. So, what is its meaning in our age of new technologies? Kuhlen (1999) put forward a suggestion which offers a very useful basis for further discussion. His theory concerns two interrelated chains of terms. In the field of IT he uses the terms "data", "knowledge" and "information" and in the field of linguistics he refers to the commonly used semiotic levels "syntax", "semantics" and "pragmatics". Connecting these two fields we can simply say that in pragmatics we deal with the application of information, in syntax we deal with the inner and outer structure of data, and in knowledge we deal with the sense of it all, the truth of a matter and also with education. Naturally, Kuhlen is aware of all the limiting aspects implied when he talks of Enlightenment in education with special emphasis on the "autonomy of knowledge".

"Autonomy of knowledge is an aim possibly never to be achieved in our bourgeois society; being able to solve one's problems with one's own resources of knowledge. Today, autonomy of information is a realistic aim. Autonomy of information is not equivalent to having already gained full knowledge. The result of the process of collecting information by means of IT helps to create autonomy of information".

Admittedly, all this reasoning remains to be determined by the emotionalism of Enlightenment. Discussions of pedagogics with "postmodern knowledge" (Lyotard 1994) are largely confined to academic circles and have hardly influenced the training of student teachers.

\section{THE STUDIENSEMINAR HAMM PROJECT}

Against the background of the above we would like to highlight the project of the Studienseminar Hamm, an institution in which future teachers for schools of higher education are trained. This institution is typical of others in many federal states in Germany. After completing their training at university, the young teacher trainees spend two years of their second stage of training at schools and at the seminarium. The schools and the seminarium co-operate closely to continue the training on a practical and 
theoretical level. Because of the underlying inner structure - where several partners share the training and the participating schools are spread over a wide area - efficient forms of training and co-operation have had to be developed. Hamm started off by building up a network for electronic communication (e-mail, etc.). On this basis, and in co-operation with the University of Dortmund, so called virtual learning stations are being installed, enabling polylocal and asynchronical work to take place, complementing the conventional education in classrooms and in face-to-face seminars. Though still in its early stages, many interesting developments relevant to our topic "new technologies and society" have emerged from this project.

- The structural arrangement of learning stations leads to on-the-spot articulation of problems which arise in the trainees' direct surroundings (his/her school), which then can be resolved through immediate investigation. In this process the young teachers find it very helpful to be able to rely on the categories of "knowledge management", such as "generating/accumulating knowledge", "communicating knowledge", "presenting knowledge" and "using knowledge". Using these categories they are made aware of basic structures of problem solving processes. This in turn gives rise to hope that a transfer on other areas of work will take place.

- The solution of (among others) technical questions requires a flexibility that traditional bureaucracies can not achieve. Sooner or later this forces the rearrangement of traditional hierarchies into smaller, interrelated units within a network. A short term measure by well-informed school authorities in reaction to this development is to allow for as much freedom to act as possible.

- A clearly recognisable rectification and interrelation of the stages of teacher training can be observed. Working at learning stations requires certain IT qualifications and the contents of learning stations are made available for the third stage in teacher training.

- Virtual learning stations allow for individual as well as cooperative learning. From a didactical point of view an in-depth evaluation of the work at learning stations promises to give an insight into and improvement of the individual and cooperative learning processes.

- The dynamics of the developments of new technologies subversively influences conventional and traditional understanding of roles, i.e. the separation of trainer and trainee. At best trainers may become consultants, but occasionally they become students again. 


\section{Acknowledgement}

Special thanks to Klaus-Peter Krause and Bernd Freyer for their assistance in translation!

\section{REFERENCES}

Foucault, M. (1977) Überwachen und Strafen. Die Geburt des Gefängnisses. Suhrkamp, Frankfurt am Main.

Holzkamp, K. (1995) Lernen. Subjektwissenschaftliche Grundlegung. Campus, Frankfurt am Main.

Kuhn, T. S. (1962) The Structure of Scientific Revolutions. University of Chicago, Chicago.

Kuhlen, R. (1999) Die Konsequenzen von Informationsassistenten. Was bedeutet informationelle Autonomie oder wie kann Vertrauen in elektronische Dienste in offenen Informationsmärkten gesichert werden? Suhrkamp, Frankfurt am Main.

Lyotard, J-F. (1994) Das postmoderne Wissen: ein Bericht. Passagen Verlag, Wien.

Merton, R. K. (1972) Die Priorität bei wissenschaftlichen Entdeckungen. Ein Kapitel der Wissenschaftssoziologie. In Wissenschaftssoziologie, volume 1, Wissenschaftliche Entwicklung als sozialer Prozess, P. Weingart (ed.), Athenäum, Frankfurt am Main.

Storer, N. W. (1972) Das soziale System der Wissenschaft. In Wissenschaftssoziologie, volume 1, Wissenschaftliche Entwicklung als sozialer Prozess, P. Weingart (ed.), Athenäum, Frankfurt am Main.

Wessner, M., Pfister, H-R. and Miao, Y. (2000) Umgebungen für computerunterstütztes kooperatives Lernen in der Schule. Informatica didactica1, No. 1.

[http://didaktik.cs.uni-potsdam.de/InformaticaDidactica/Issue1/] 